\title{
'Academic periodization': using approaches from elite sport to benefit early career academics
}

\author{
Kevin Deighton*,1 \& Javier T Gonzalez ${ }^{2}$ \\ ${ }^{1}$ Institute for Sport, Physical Activity \& Leisure, Leeds Beckett University, Leeds, LS6 3QS, UK \\ ${ }^{2}$ Department for Health, University of Bath, Bath, BA2 7AY, UK \\ *Author for correspondence: K.Deighton@leedsbeckett.ac.uk
}

\author{
"As academics with an interest in exercise science, we believe that several approaches and \\ concepts from the world of elite sport may be used to benefit the work of early career \\ academics."
}

First draft submitted: 1 December 2018; Accepted for publication: 5 February 2019; Published online: 2 May 2019

\begin{abstract}
Keywords: burnout $\bullet$ early career researchers $\bullet$ efficiency $\bullet$ health $\bullet$ performance $\bullet$ reflective practice $\bullet$ tenure $\bullet$ working intensity $\bullet$ work-life balance $\bullet$ workload
\end{abstract}

Working in academia can be a pleasure and a privilege. Benefits of this role include high levels of mental stimulation, the pursuit of new knowledge and understanding, opportunities to nurture engaged students, and the study of interesting topics. Indeed, the work of many academics overlaps with a natural interest which can blur the line between leisure-time activities and employment. Nevertheless, many challenges and difficulties also exist in a climate of substantial pressures, demands and responsibilities. These pressures may be enhanced in the experiences of early career academics as staff try to balance a variety of new responsibilities, including teaching, research and administrative roles.

As academics with an interest in exercise science, we believe that several approaches and concepts from the world of elite sport may be used to benefit the work of early career academics. One such concept is periodization, which broadly describes the planning of training and nutritional intakes to stimulate specific physiological adaptations aimed at maximizing performance, while minimizing the risk of overtraining and injury [1,2]. This can be mirrored in an academic context through planned approaches for the achievement of progressive goals to reach major objectives. Our model of academic periodization aims to apply this concept to support efficiency and performance, while minimizing the risk of overworking or burnout among young academics.

\section{Long-term periodization}

Periodization involves planning backward from a primary overarching aim. In elite sports, the target is often a major competition, such as the Olympic Games, which would require planning for the 4-year cycle between events. Accordingly, case studies of successful Olympic athletes have reported the efficacious targeting of progressive annual improvements in physiological development and performance during this 4-year period [3]. Such planning with a long-term focus for progressive development may be especially relevant for early career academics who are establishing themselves within a field. Many institutions have an academic probation period of 3-5 years, during which they have the chance to establish this career foundation. In this regard, the development of an appropriate track record of small funding grants, data collection and publications seems essential for the generation of major external research funding. Herein lies an additional analogy to sport, whereby large grants are almost always improved when collaboration is included, where people with unique expertise can pull together to achieve a goal that would otherwise be impossible for an individual. Potential approaches for periodizing academia across timeframes of years, months, weeks and days are provided in the sections below. The parallels with elite sport are considered throughout. 


\section{Annual \& monthly periodization}

Annual periodization in a sporting context involves progression through specific training phases to target key adaptations, preparation activities and performance objectives [4]. Equally, an academic cycle may focus on aspects of specific method development to enable data collection and writing to achieve annual goals of journal article publications and grant applications. It is important to note within a sporting context that athletes 'peak' for optimal performance at specific points during the year because attempts to maintain optimal form for excessive periods increases the risk of overtraining and burnout. For example, a Tour de France cyclist will achieve a body mass during the 3-week competition in July that would be dangerously low if maintained constantly throughout the year. Equivalently, 'peak' phases exist within an academic cycle where there is greater opportunity to perform the high intensity work required with research activity, but if this were to be sustained throughout the year, this could have a detrimental impact on mental or physical health.

Planning specific research activities in relation to the corresponding workload from teaching and administrative responsibilities may benefit efficiency and productivity. Considerations within this approach include planning which aspects of research momentum can be maintained at different stages of the academic cycle. For example, it may not be achievable to write large grant applications and publications during the months of the year when teaching and administrative responsibilities are most demanding. However, it may still be feasible to continue aspects of data collection, data processing or skill development. Equivalently in endurance sport, efforts to maximize finishing speed occur at different stages of a season than efforts to maximize aerobic fitness, due to confliction in the physiological load required for these adaptations. Ultimately, the appropriate timing of these stages in an athletic cycle facilitates optimal development toward targeted annual goals [5]. Such planning for different stages of the academic year to maintain research momentum can provide a platform for the completion of more advanced research activities during the 'peak' phase of an academic cycle when other competing demands have reduced. The periodization of an academic year may also consider how demands differ between semesters and when 'peak' opportunities for research delivery will be present. Evidently, planned activities within the periodization model must be successfully completed for the achievement of research aims, which emphasizes the need to avoid any substitution of these high-intensity research activities with less demanding tasks.

\section{Daily \& weekly periodization}

Daily and weekly periodization requires an appropriate balance between low, moderate and high-intensity activities to optimize adaptations and progress while ensuring sufficient recovery [5]. As with the categorization of exercise intensities, the varied tasks involved in academic roles can be broadly classified as being low, moderate or highintensity according to their cognitive demands. For example, the synthesis of new knowledge represents a highintensity activity, while moderate intensity activities may include aspects of teaching preparation, and low-intensity activities may include attendance at administrative meetings, basic data inputting or the processing of generic emails. However, it is important to acknowledge that the intensity of different activities may vary between contexts and the reader is therefore encouraged to consider the relative intensities of the tasks completed within their respective roles.

The synthesis of new knowledge through research activities is undoubtedly a high-intensity activity, which makes it important to prioritize this activity for maximal performance during the most productive periods of a day. Although this may differ between individuals, performing these tasks earlier in the working day may be beneficial where possible to avoid preceding fatigue from lower intensity activities. This approach would also enable the scheduling of low and moderate intensity activities (e.g., meetings or emails) as a break from high-intensity tasks to protect against excessive fatigue. A similar approach for balancing these activities can also be planned across weekly schedules to maximize productivity while limiting the risk of burnout.

The planned periodization of tasks within a day can also be an important consideration for minimizing 'task switching', which can impair working memory and consequently reduce performance during high-intensity academic activities. Indeed, focusing on a single task while minimizing other distractions has been shown to increase the efficiency and quality of task completion $[6,7]$. The consideration to check emails as a scheduled break from high-intensity activities and turning off alerts during high-intensity tasks represent common examples of strategies to discretely periodize activities within a day. 


\section{Summary}

Academic periodization is based on concepts used to optimize elite sporting performance and this may represent an effective approach to help young academics reflect on their working practices in order to meet the demands of their roles. The focus on maximizing efficiency hopes to benefit performance, but also to reduce the risk of early career academics engaging with excessive working hours. The core principle of rest must also be considered within this model of periodization and it is hoped that improved efficiency can increase opportunities for rest and recovery within the academic cycle.

\section{Financial \& competing interests disclosure}

The authors have no relevant affiliations or financial involvement with any organization or entity with a financial interest in or financial conflict with the subject matter or materials discussed in the manuscript. This includes employment, consultancies, honoraria, stock ownership or options, expert testimony, grants or patents received or pending, or royalties.

No writing assistance was utilized in the production of this manuscript.

\section{Open access}

This work is licensed under the Attribution-NonCommercial-NoDerivatives 4.0 Unported License. To view a copy of this license, visit http://creativecommons.org/licenses/by-nc-nd/4.0/

\section{References}

1. Sylta Ø, Tønnessen E, Hammarström D et al. The effect of different high-intensity periodization models on endurance adaptations. Med. Sci. Sports Exerc. 48, 2165-2174 (2016).

2. Impey SG, Hearris MA, Hammond KM et al. Fuel for the work required: a theoretical framework for carbohydrate periodization and the glycogen threshold hypothesis. Sports Med. 48, 1031-1048 (2018).

3. Rasdal V, Moen F, Sandbakk Ø. The long-term development of training, technical, and physiological characteristics of an Olympic champion in nordic combined. Front. Physiol. 13, 931 (2018).

4. Solli GS, Tønnessen E, Sandbakk Ø. The training characteristics of the world's most successful female cross-country skier. Front. Physiol. 18, 1069 (2017).

5. Kenneally M, Casado A, Santos-Concejero J. The effect of periodization and training intensity distribution on middle- and long-distance running performance: a systematic review. Int. J. Sports Physiol. Perform. 13, 1114-1121 (2018).

6. Draheim C, Hicks KL, Engle RW. Combining reaction time and accuracy: the relationship between working memory capacity and task switching as a case example. Perspect. Psychol. Sci. 11, 133-155 (2016).

7. Foroughi CK, Werner NE, Nelson ET et al. Do interruptions affect quality of work? Hum. Factors. 56, 1262-1271 (2014). 